\title{
Anticoagulant and vasodilator therapy for Nicolau syndrome following intramuscular benzathine penicillin injection in a 4 year old boy
}

\author{
Tijen Alkan Bozkaya, M.D. ${ }^{a}$, Gamze Demirel, M.D. ${ }^{b}$, Tugrul Ormeci, M.D. ${ }^{c}$, Serdar Al, M.D. ${ }^{d}$, \\ Engin Çakar, M.D. ${ }^{e}$, Ayhan Tastekin, M.D. ${ }^{b}$ and Halil Turkoglu, M.D. ${ }^{a}$
}

\begin{abstract}
Nicolau syndrome (NS) is a rare complication of intramuscular, intraarticular or subcutaneous injection of particular drugs leading to ischemic necrosis of the surrounding skin, soft tissue and muscular tissue. Benzathine penicilin one of the most widely used antibiotic for upper respiratory tract infections and has been rarely reported to cause NS. Here we describe a 4 year old boy with diagnosis of NS after the injection of benzathine penicillin who was successfuly treated with unfractionized heparin (enoxaparine) and pentoxifylline. The practitioners should pay attention for unnecessary use of benzathine penicillin to avoid from probable complications.

Key words: Nicolau syndrome, benzathine penicillin, enoxaparine, pentoxifylline.
\end{abstract}

http:/ /dx.doi.org/10.5546/aap.2016.eng.e184

Nicolau syndrome (NS), also known as embolia cutis medicomentosa or livedo-like dermatitis, is a rare complication of intramuscular, intraarticular or subcutaneous injection of particular drugs leading to ischemic necrosis of the skin, soft tissue and muscular tissue. ${ }^{1,2} \mathrm{NS}$ has been reported with the administration of various drugs like antibiotics, local anesthetics, corticosteroids and non steroidal antiinflamatory drugs. ${ }^{3-7}$

a. Department of Cardiovascular Surgery, Istanbul Medipol University, Istanbul.

b. Division of Neonatology, Department of Pediatrics, Istanbul Medipol University, Istanbul.

c. Department of Radiology, Istanbul Medipol University, Istanbul.

d. Department of Pediatrics, Istanbul Medipol University, Istanbul.

e. Department of Physical Medicine and Rehabilitation, Istanbul Medipol University, Istanbul. Turkey.

E-mail Address:

Gamze Demirel, M.D.: fgdemirel@medipol.edu.tr

Funding: None.

Conflict of interest: None.

Received: 10-10-2015

Accepted: 12-16-2015
The pathogenesis of NS is not clear. In the previous years, accidental intraarterial injections were blamed as the etiology. ${ }^{8}$ Recently, the proposed mechanisms are acute vasospasm, arteritis and thromboembolic occlusion of small arteries. ${ }^{9}$ The typical presentation is pain around the injection site, followed by erythema, livedoid patch and recently necrosis of the soft tissue. ${ }^{3,9,10}$ Here we report a 4 year old boy who was diagnosed NS after intramuscular benzathine penicillin injection and treated completely with vasoactive and antithrombotic therapy.

\section{CASE REPORT}

A 4 year old boy was referred to our emergency department with right lower extremity pain and edema. The symptoms developed within hours after intramuscular benzathine penicilin injection, dosage of $600,000 \mathrm{IU}$, for acute upper respiratory tract infection. Physical examination revealed echimosis around the injection site, within minutes livedoid skin changes and then ischemic pattern was seen (Figure 1,2). A few hours later, rash and swelling expands to the entire leg. The child had strong pain and partial motor deficit at the lower part

FIGURE 1. Physical examination revealed purpuric rash around the injection site, within minutes livedoid skin changes and then ischemic pattern was seen.

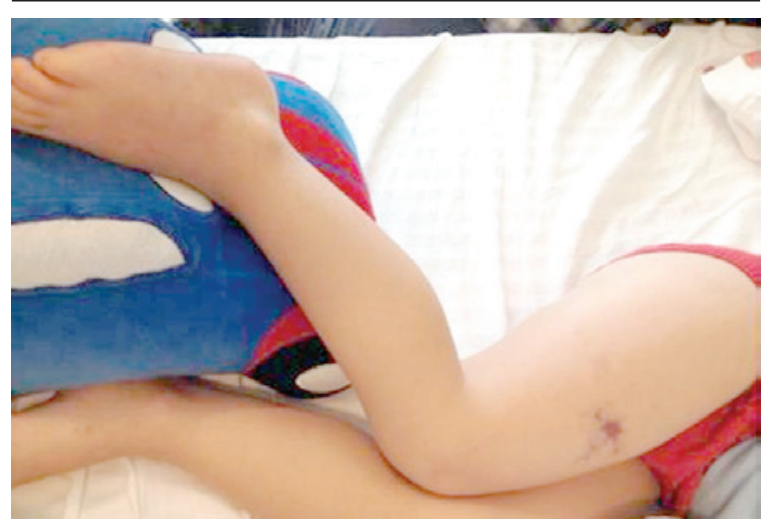


of the leg. Ultrasonography (USG) showed soft tissue swelling at the peri-injection site and diffuse heterogenous aspect and edema within the subcutaneous fat layer and muscular tissue (Figure 3). Vital signs were stable. There was no evidence of infection or hematologic disorder on laboratory parameters. Clinically the patient was diagnosed as NS. He was hospitalized and fractioned heparin $\left(\right.$ Clexan $^{\circledR}$, subcutaneously), dextran (Rheomacrodex ${ }^{\circledR}$ ) and pentoxifylline $\left(\right.$ Trental $\left.{ }^{\circledR}\right)$ were used for medication. These

FIGURE 2. A few hours after the purpuric rash around the injection site, rash and swelling expands to the entire leg.

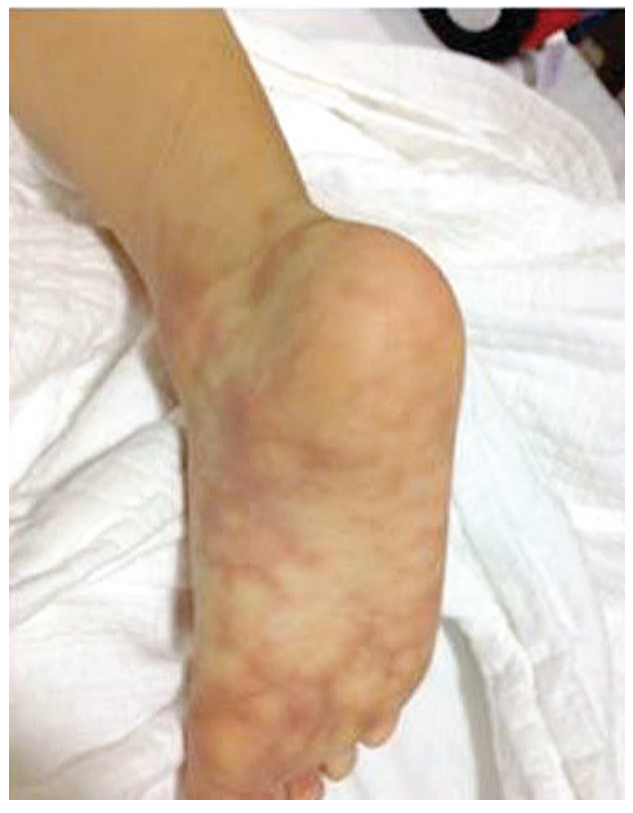

antithrombotic and vasodilator therapy was started within the first hour of hospitalization, fractionized heparin dose was $1.5 \mathrm{mg} / \mathrm{kg} /$ dose, twice a day given for 8 days and pentoxifylline dose was $10 \mathrm{mg} / \mathrm{kg} /$ day, given for 4 days. After the 4 th day of hospitalization, he began to walk normally and motor deficit resolved completely. The control of USG showed regressed edema within the subcutaneous fat layer and muscular tissue compared with the first USG.

\section{DISCUSSION}

Nicolau syndrome is a rare, unexplained complication of intramuscular, intraarticular or subcutaneous injection of many drugs, characterized by aseptic necrosis of the soft tissue. ${ }^{11}$ It was first described by Nicolau ${ }^{11}$ in 1925 , after the use of intramuscular bismuth salts for treatment of syphilis. It has been associated with several drugs like antibiotics, corticosteroids, nonsteroidal antiinflamatory drugs, sedatives and vaccines. ${ }^{9,12}$ Penicillin is one of the antibiotics that is associated with NS. ${ }^{13-15}$ The pathogenesis is unknown but the most possible hypothesis is initial vascular injury with local inflamation, reflex arterial spasm, local arterial thrombosis and vascular occlusion by microemboli. ${ }^{9}$ Most important in the prevention of this syndrome is the use of proper technique of applying medication and aspiration before injection and use small amounts of medication to inject (it issuggested to be $<5 \mathrm{ml}$ per site application).

The diagnosis is based on clinical presentation and the first manifestation is severe local pain immediately after injection of the drug. Afterwards, pallor, cyanotic patches and

FIGURE 3. Axial ultrasonographic images. Increased both thickness and echogenicity in subcutaneous fat layer are seen (asterisk). A-There is also enlargement of right rectus femoris muscle (RF) which is injection site. B-Edema in subcutaneous fat layer and enlargement of muscle are decreased in follow-up sonography.

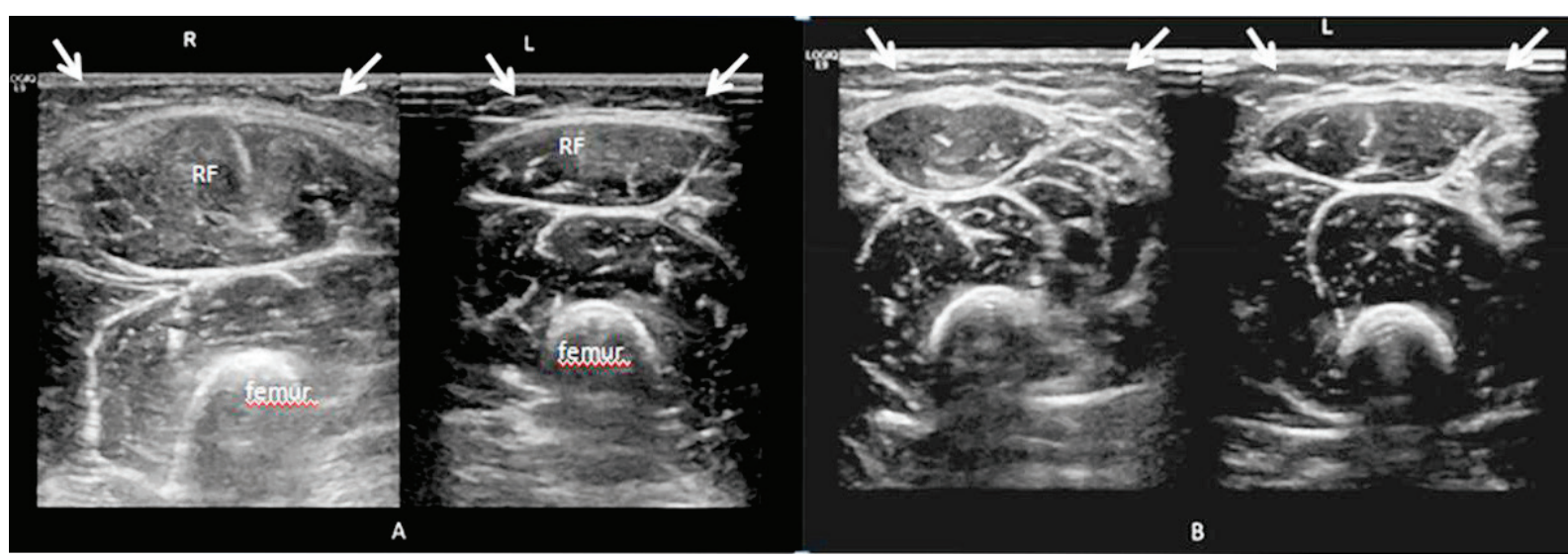


livedoid appearence is seen, sometimes leading to local necrosis. ${ }^{7}$ Our patient was referred to our department with severe local pain and echimosis at the injection site. Neurologic impairment is rarely seen in NS. ${ }^{5}$ Our patient has partial motor deficit at the lower part of the leg and could not walk for four days after the event.

Treatment is symptomatic as pain control, antibiotic prophylaxis and conservative surgical interventions. ${ }^{7}$ There are some literature who report the efficacy of vasodilators, anticoagulants and systemic steroids. ${ }^{10}$ The literature about anticoagulant treatment is limited. In our case, we used unfractionized heparin (enoxiparin), dextran and pentoxifylline, and received great benefit. Hyperbaric oxygen was reported to be efficient when there is a reperfusion injury..$^{15}$ The prognosis is variable, potentially fatal condition showing variable levels of tissue necrosis. Systemic infection and renal dysfunction due to rhabdomyolysis may cause death.

In conclusion, physicians must be aware of possible complications of intramuscular injections and should avoid unnecessary injection in children. Anaphylaxis is a feared complication of penicillin injection, but complications of intramuscular injection are not limited to these widely recognized problems. NS should be kept in mind in specific clinical appearence after the particular drug injections. Benzathine penicillin is one of the most misabused drugs for upper respiratory tract infections and should be used more cautiously to avoid from probable complications.

\section{REFERENCES}

1. Kim SK, Kim TH, Lee KC. Nicolau syndrome after intramuscular injection: 3 cases. Arch Plast Surg 2012;39(3):249-52.

2. Senel E. Nicolau syndrome as an avoidable complication. J Family Community Med 2012;19(1):52-3.

3. EzzedineK,Vadoud-SeyediJ,Heenen M.Nicolausyndrome following diclofenac administration. $\mathrm{Br} \mathrm{J}$ Dermatol 2004;150(2):385-7.

4. Senel E, Ada S, Gülec AT, Caglar B. Nicolau syndrome aggravated by cold application after i.m. diclofenac. $J$ Dermatol 2008;35(1):18-20.

5. Lee DP, Bae GY, Lee MW, Choi JH, et al. Nicolau syndrome caused by piroxicam. Int J Dermatol 2005;44(12):1069-70.

6. Modzelewska I, Dawidowicz-Szczepanowska A. Nicolau syndrome following administration of procaine penicillin. Wiad Lek 1980;33(3):231-3.

7. Cherasse A, Kahn MF, Mistrih R, Maillard H, etal. Nicolau's syndrome after local glucocorticoid injection. Joint Bone Spine 2003;70(5):390-2.

8. Stiehl P, Weissbach G, Schröter K. Nicolau syndrome. Pathogenesis and clinical aspects of penicillin-induced arterial embolism. Schweiz Med Wochenschr 1971;101(11): 377-85.

9. Luton K, Garcia C, Poletti E, Koester G. Nicolau Syndrome: three cases and review. Int J Dermatol 2006;45(11):1326-8.

10. Lie C, Leung F, Chow SP. Nicolau syndrome following intramuscular diclofenac administration: a case report. $J$ Orthop Surg (Hong Kong) 2006;14(1):104-7.

11. Nicolau S. Dermite livedoide et gangreneuse de la fesse, consecutive aux injections intra-muscularies dans la syphilis; a propos d'un cas d'embolic arteriellebismuthique. Ann Mal Vener 1925;20:321-9.

12. Cockshott WP, Thompson GT, Howlett LJ, Seeley ET. Intramuscular or intralipomatous injections? $\mathrm{N}$ Engl J Me 1982;307(6):356-8.

13. Noaparast M, Mirsharifi R, Elyasinia F, Parsaei R, et al. Nicolausyndrome after intramuscular benzathine penicillin injection. Iran J Med Sci 2014;39(6):577-9.

14. Benmiloud S, Hida M. Nicolau syndrome complicating an intramuscular injection of benzathine penicillin. Pan Afr Med J 2014;18:105.

15. Karimi M, Owlia MB. Nicolau syndrome following intramuscular penicillin injection. J Coll Physicians Surg Pak 2012;22(1):41-2. 